\section{Geology and health: closing the gap}

\section{H. Catherine W. Skinner and \\ Antony R.Berger (Eds.)}

Oxford University Press, 2003, 192

pages, 9 halftones \& 41 line illus.,

US\$75.00, ISBN 0-19-516204-8.

It was discovered several decades ago that the natural geo-environment could substantially impact on the health of animals and humans. However, despite the growth of evidence supporting this discovery, there has not been a close interaction between geoscientists and health scientists in assessing the need to study the various facets of the relationships between human and animal health and air, water, soils and rocks. This book is timely in closing that gap as stated in its title.

The book contains 26 contributions that are divided into three major themes: (1) Natural Geological Hazards have been subdivided into health hazards that are triggered by natural dust and eruptions and those related to long-term exposure to geochemical anomalies; (2) Anthropogenic Geo-environmental Hazards, e.g. mining pollution or industrial lead $(\mathrm{Pb})$ environmental poisoning; (3) global and local case studies focusing on the identification and description of geo-environmental hazards.

The $1^{\text {st }}$ Chapter of this book (Berger) provides the framework in which the new field of geology coined as Medical Geology is being developed, and outlines the challenges ahead, e.g. how to reduce geoenvironmental threats to the health of humans and animals. The $2^{\text {nd }}$ Chapter (Derbyshire) reviews the link between natural wind-blown dust (aerosols) and pneumoconiosis in High Asia. Although similar relationships were reported in other arid environments, the effect of such far-traveled silty mineral particles on the health of humans has received little attention in some regions of the world, e.g. in the Kalahari desert of southern Africa. The $3^{\text {d }}$ Chapter (Grattan et al.) assesses human sickness and mortality rates that relate to volcanic gases using the 1783 Laki fissure eruption (Iceland) as an example. This case study shows how the interplay of particular environmental (in this case meteorological) parameters with volcanic gases can trigger severe health issues at great distances from the volcanic source. This case study is reminiscent of a more recent catastrophe in which the interaction between water and volcanic gases at Lake Nyos induced a major human disaster in Cameroon. The $4^{\text {th }}$ Chapter (Abrahams) reviews the distribution, causes and implications of human geophagy and health issues originating from ingesting unsuitable or excessive quantities of soil. Chapter 5 (Naidu and Nadebaum), Chapter 6 (Finkel-

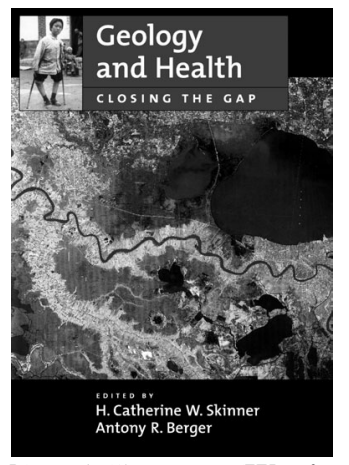

man et al.) and Chapter 7 (Wuyi et al.) are devoted to high arsenic (As) contents and human health. These three papers briefly review the basic chemical characteristics of As, its host minerals and its transfer pathways in the environment, e.g. transfer from minerals to surface and groundwater, soils, plants and animals/humans. Arsenic and fluorine pollution related to coal mining activities and consumption is highlighted and the remediation techniques for arsenic from water are included. Chapter 8 (Steinnes) and Chapter 9 (Fordyce et al.) are devoted to iodine and its biogeochemical cycle and on iodine deficiency in the environment and its link to Iodine Deficiency Disorders (IDD) respectively. Both papers clearly show the need for a better understanding of the bioavailability of an element in a specific environment (rather than analyzing only its total content) when assessing its impact on health issues and in developing its environmental remediation strategies. Chapter 10 (Lindh et al.) and Chapter 11 (Lindvall et al.) are devoted to mercury with particular emphasis on the effect of mercury from dental amalgam. Chapter 12 (Gough et al.) deals with the transport and bioaccumulation of heavy metals (cadmium in this case) and how allochtonous (e.g. aeolian) soils and/or soil's organic matter content rather than bedrock composition can control their uptake by vegetation. This chapter stresses the enrichment process from soils to vegetation, leading to herbivore health issues from heavy metal intake through vegetation. Chapter 13 (Frank) demonstrates the relationships between molybdenosis (and related copperdeficiency) and Type 2 Diabetes Mellitus in moose, using experimental studies conducted on goats. Chapter 14 (Neal) addresses the close link between fresh water and Human/Animal Health. It particularly highlights: (1) the main geo-environmental factors controlling surface and groundwater quality and (2) the role of natural inorganic components (e.g. elements/minerals/rocks), anthropogenic organic/inorganic compounds and harmful biological species in water quality. This chapter discusses important scientific and policy issues related to natural and anthropogenic (cf. industrialization) water pollution using a U.K. case study and provides examples of surface water and groundwater quality control and management in relation to human health. Chapter 15 (Plant and Davis) documents the sources and pathways of endocrine-disrupting chemicals (EDCs) on breast and prostate cancer. Chapter 16 (Grattan et al.) and Chapter 17 (Robbins and Harthill) provide an insight into modern and past environmental and health issues in old copper mining and smelting sites. In particular they show the need for copper and all other transition metal speciation studies in mining provinces in the world. Chapter 18 (Hillerdal) is devoted to health hazards related to fibrous minerals commonly known under the commercial name "Asbestos" whereas Chapter 19 (Mielke et al.) focuses on Lead $(\mathrm{Pb})$-related health issues, particularly in urban environments. Indeed the rapid growth of urban areas throughout the world in both developed and developing countries requires environmental geochemical base maps to monitor and manage adequately $\mathrm{Pb}$ and other heavy metal contamination. Chapter 20 (Plant et al.) reviews critical aspects of environmental geochemistry on a global scale, particularly stressing the need to further support the worldwide development of the global geochemistry database that provides a baseline for monitoring future environmental pollution. Chapter 21 (Selinus) shows that biogeochemical monitoring using aquatic mosses and roots of aquatic higher plants could provide more sensitive tools for tracking metal pollution in stream water. Chapter 22 (Davies) is a review of various health issues related to geoenvironmental factors in East and Southern Africa. Chapter 23 (Skinner) provides an insight into the complex linkage between environmental geochemistry, mineral chemistry, biogeochemistry and vertebrate bones. Chapter 24 (Ceruti et al.) reports a case study on the relationships between soil nutrient deficiencies, Endemic Osteoarthritis (Mseleni Joint Disease) and Dwarfism. Chapter 25 (Pawlikowski) focuses on minerals (hydroxylapatite) in human blood vessels and their dissolution in vitro. Chapter 26 (Tatu et al.) presents a strong case for a direct correlation between organic compounds from Pliocene lignite and the Balkan Endemic Nephropathy (BEN), a chronic and irreversible kidney disease confined to the alluvial valleys of tributaries of the lower Danube river.

This book is concluded by a summary of the main achievements of Medical Geology, opportunities emerging from this new science subject and provides important avenues for future research. The large spectrum and the diversity of topics compiled in this book allow the reader to acquire a broad understanding of the variety of health issues originating from geo-environment factors. Furthermore, each Chapter includes a reference list to allow readers to expand their knowledge beyond the book's content. The 26 chapters covered in this book were written by 65 experts from Africa, America, Asia, Australia and Europe, confirming the value of sharing knowledge beyond national and continental boundaries in order to better 
learn the complexity of relations between geo-environmental parameters and health issues. This book shows that building a sustainable world requires a close collaboration between Earth scientists and Health scientists. The International Union of Geological Sciences and UNESCO have recently confirmed this by selecting the topic Earth \& Health as one of the eight main themes of research to be supported by the United Nations International Year of the Planet Earth in 2005. The book by Skinner and Berger on "Geology and Health" is certainly a forerunner of more books to come from this crossroad area between Medicine and Earth Sciences

The introduction to this team book (Skinner and Berger) provides a general framework in which this book was prepared and stresses its strength and shortcomings. Among the shortcomings, Skinner and Berger underline that: (1) the Chapters are neither fully developed statements of research efforts nor comprehensive treatments of specific issues; (2) the (broad) range of expertise involved (medical, dental, veterinary and geological) leads to a diversity in the style and format of the papers submitted. After reading this book in detail twice, I am of the opinion that, rather than these being shortcomings, the strength of this book comes from its cross-disciplinary approach and the diversity of topics covered in a reasonable number of pages. On the basis of these two elements, I recommend this book to all geoscientists and health professionals. This is a valuable book for both under- and post-graduate environmental geology and environmental health courses.

Prof. A.B. Kampunzu

Department of Geology

University of Botswana

Gaborone

BOTSWANA

E-mail:Kampunzu@mopipi.ub.bw

\section{Mantle plumes and their record in Earth history}

\author{
By Kent C. Condie
}

Cambridge University Press, 2001. 306

pp. UK, Paperback: $£ 27.95$, ISBN

0521014727; Hardback: $£ 75.00$, ISBN

0521806046.

In recent years, the study of mantle plumes has become a "hot spot" in earth sciences; enormous papers and data have been published, and many mantle plume-related questions have arisen: Did mantle plumes in the Precambrian behave the same way as they do today? What are the roles of plumes in the evolution of the earth? What are the effects of mantle plumes on global changes and metallogenesis? These issues are frequently encountered and hotly debated in a wide range of earth science fields such as tectonics, geochemistry, geophysics, metallogenesis, etc. To better understand the origin of mantle plumes and the chemical and physical processes involved in mantle evolution, it is crucially important to have integrated information about mantle plumes. Mantle Plumes and Their Record in Earth History written by Kent C. Condie may meet this need. With 103 black-white figures and 4 colored plates, an alphabetic index, and over 700 cited references, this book provides a comprehensive and informative review of updated research results of mantle plumes, which includes well organized fundamental principles, descriptions, generalizations and immense amount of factual data from a wide range of fields.

The book includes nine chapters: introduction, hotspots and mantle upwelling, large igneous provinces (LIP), mantle plumes generation and melting, plumes as tracers of mantle processes, mantle plumes and continental growth, mantle plumes in the Archean, superplume events, and mantle plumes and earth systems. The author begins with general features of mantle plumes and nomenclatures applied to mantle plumes, which serve as the basis for the subsequent descriptions and discussions. These are followed by descriptions of the structure of the lithosphere and mantle reflected by geophysical data, such as the "D" Layer, the 440-km and $660-\mathrm{km}$ discontinuities, etc. On the basis of these, the author elucidates the relationship of mantle plumes with convection in the mantle, which links mantle plumes with the plate tectonics.

The beginning part of the main body (Chapters 2 and 3) focuses on hotspots and large igneous provinces (LIP), and establishes a framework of mantle plumes operating in the earth and other planets including Mars and Venus. The descriptions include spatial distribution of hotspot tracks, volcanic chains, seamount arrays, and mantle upwellings, which are accompanied with

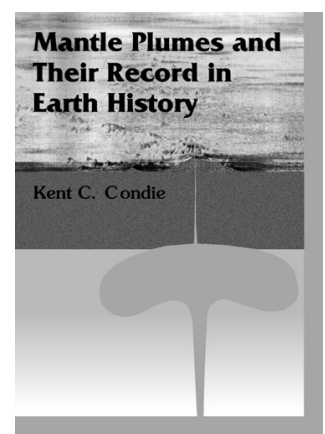

results of laboratory work and numerical experiments. These are followed by analysis of the relationship between hotspots and mantle plumes and their roles in plate tectonics and earth evolution. Many striking igneous suites in the crust are listed as evidence of plumes and to illustrate the mantle plume-related processes, which include volcanic chains, flood basalts, dyke swarms, layered intrusives, and kimberlites. The Bushveld Complex is cited as one of the plume-related examples. Also cited as evidence of mantle plumes are the large igneous provinces on Mars and Venus.

Subsequently, the author examines the mechanism of the origin and evolution of mantle plumes (Chapter 4). Supported by experimental and numerical models, the author describes plume characteristics and discusses generation and melting of mantle plumes. The discussion is according to plate tectonics, and the evolution of the mantle plumes is genetically linked to plate tectonic processes, from ocean ridge spreading to subduction, in order to explain the causes of, and controls over the generation and melting of mantle plumes and their interaction with the lithosphere. Also discussed is the reason why mantle plumes are located in low latitude territories. Even though we are still not absolutely certain about how mantle plumes are formed and why they are located as they are, we have seen the prominent correlation between the plumes tracers and plate tectonics.

Chapter 5 reviews geochemical and isotopic evidence for the existence of mantle plumes. It discusses geochemical and isotopic signatures of igneous rocks derived from the plumes, which are the key to identification of mantle plumes. With a detailed review of published trace element and isotope data, e.g., the $\mathrm{Nb} / \mathrm{U}, \mathrm{Th} / \mathrm{Ta}, \mathrm{La} / \mathrm{Yb}$ ratios, and $\mathrm{Os}, \mathrm{He}$ and $\mathrm{O}$ isotopes of the mantle- and crust-derived rocks, the author discusses the fingerprints of magmas from different source regions, which carry information of mantle processes. Examples of these include the high- and low-Ti basalts in flood basalt provinces, which are interpreted as magmas derived from mantle plume heads and surrounding lithosphere, respectively.

From a geodynamic point of view, Chapter 6 and 7 explore the possible role of mantle plumes in the evolution of the planet based on the preserved geological record. After reviewing examples of accretion of oceanic plateaus to the continents in the last 
100 million years, including the oceanic plateaus in Caribbean, the American Cordillera, and Japan, the author discusses the possible role that mantle plumes may have played in the growth of continents. It is proposed that mantle plumes have contributed to the growth of continental crust by accretion of oceanic plateaus (products of mantle plumes) to the continental margin via underplating. This model sheds light on interpretation of the complexities of continental crust, such as how underplating by plume-generated assemblages could have significantly varied the structure and components of the continental crust.

The Precambrian plate tectonics issue, and Archean tectonics in particular, has been debated for decades. Even though many details about the Archean plate tectonics are still unknown, many models about the nature of the Archean crust and mantle have been proposed. In Chapter 7, the author analyses the origin of some of the characteristic rocks in Archean terranes: komatiites, greenstones, flood basalts, etc., and ascribes them as mantle plume-derived rocks. It is suggested that oceanic plateaus were more widespread during Archean than subsequently, and that the Archean mantle was hotter and the lithosphere was thicker than the Proterozoic and Phanerozoic. These factors could have prevented the oceanic lithosphere from subducting into the mantle. These may account for the fact that more plume-generated rocks are found in the Archean than in the younger terranes.

The aggregation and dispersion of supercontinents are focuses of geodynamics. What is the role of mantle plumes in the supercontinent cycle? In Chapter 8, the author integrates the published data and suggests that mantle plumes were responsible for supercontinent evolution, which is supported by isotopic dating of magmatism associated with the aggregation and breakup of the Rodinia, Gondwana, and Pangea supercontinents, and also by examples of basin opening in Red Sea, Gulf of Aden, and Arabian Sea. A model is proposed to illustrate the generation and breakup of a supercontinent.

In the last part of the book, as a summary, the author considers mantle plume events as part of the whole earth systems that includes the ocean-atmosphere-biosphere system. He analyses the possible effects of mantle plume-related processes on sea level changes, global warming, life, formation of $\mathrm{BIF}$, sedimentation of phosphates, etc. This provides the readers with a wide and perspective view about mantle plumes and which may interest readers from a variety of fields.

There are still many uncertainties about mantle plumes and it is very likely that many of the interpretations and statements in this book may not be totally accepted by all readers. In spite of these considerations, this book is very valuable, and provides a timely and integrated knowledge and databank that could serve as the basis for further research in this field. This book could be used as a textbook for graduate or advanced undergraduate courses in geology, geophysics, and geochemistry, and will also be very useful for researchers in relevant fields of earth sciences.

\section{Q.M.Peng}

Dept. of Science and Technology \&

International Cooperation

China Geological Survey

24, Huangsi Street

Beijing 100035

CHINA

\section{Proterozoic East \\ Gondwana: supercontinent assembly and breakup}

Edited by M. Yoshida, B.F.
Windley, and S. Dasgupta

Geological Society Special Publication 206, London, 480 pages, ISBN 186239-125-4, 110 UK Pounds/183 US Dollars.

The editors of this volume assembled a remarkable group of contributors to discuss both the geology of East Gondwana and also many related issues. The 19 papers in this book provide a wealth of information on East Gondwana, the assembly of Gondwana as a supercontinent, the configuration of Rodinia, and general problems of the origin of continental crust and movement of continental plates. They also illustrate some of the controversies, with most papers having at least some points of difference in both fact and interpretation from other papers in the book.

The book begins with two very general papers by K.C. Condie and B.F. Windley on general problems of continental growth and conitnues with reviews of the tectonics of Rodinia by S.A. Pisarevsky and colleagues and of East Gondwana by M. Yoshida. The other 15 papers are somewhat more specific, although all of them relate their areas of investigation to general problems concerning East Gondwana.

Papers by M.T.D. Wingate and D.A.D. Evans and by I.C.W. Fitzsimons describe the geology of Australia, and papers by S. Dasgupta and P. Sengupta, by C.J. Dobmeier and M.M. Raith, and by I. Braun and L.M. Kriegsman concentrate on southern India and adjoining areas, particularly the Eastern Ghats belt of eastern India.

Only 4 papers are specifically listed as sources of information on Antarctica (S.L. Harley; Y. Zhao and colleagues; W. Bauer and colleagues; and J. Jacobs and colleagues). A total of 10 papers in the volume, however, discuss the geology of East Antarctica in connection with other issues. Simi-

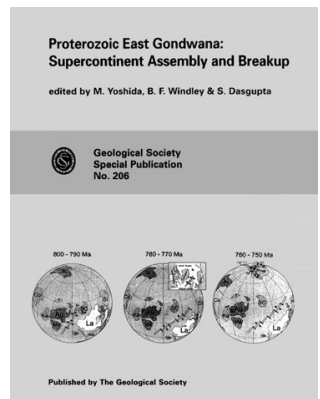

larly 6 papers are specifically oriented toward the geology of the East African Orogen (P.R. Johnson and B. Woldehaimanot; T. M. Kusky and M.I. Matsah; A.S. Collins and colleagues; A. Fernandez and G. Schreuers; G.H. Grantham and colleagues; and R. E. Hanson). Seven other papers, however, also discuss Pan-African activity in East Gondwana, indicating the importance of this time period in its geologic history.

This book is an important contribution to an understanding of East Gondwana and all of the other geologic problems that it is related to. I recommend it both for the timely review provided by the papers and the extensive reference list that each paper contains of earlier work.

\section{John J.W. Rogers}

Dept. of Geological Sciences, CB\# 3315

University of North Carolina

Chapel Hill, North Carolina 27599-3315, USA

Office phone: 919-962-2581

Home phone: 919-942-2609

Fax: 919-966-4519 